\title{
LINKAGE IN TRISOMIC INHERITANCE
}

\author{
BRUCE GRIFFING \\ Division of Plant Industry, C.S.I.R.O., Canberra, A.C.T.
}

Received 6.iii.56

\section{SUMMARY}

Application of Fisher's general theory of linkage in polysomic inheritance is made to the special case of trisomic inheritance. The enumeration and classification of (I) trisomic genotypes, and (2) monosomic and disomic gametes derived from a trisomic organism is presented. Gametic matrices are then constructed and the estimation procedures for various genetic parameters are outlined. Finally a numerical example is given.

\section{INTRODUCTION}

The general theory of linkage in polysomic inheritance has been developed primarily by Fisher in two remarkable papers (Fisher, 1947, 1950). Application of the polysomic theory has been made to those organisms in which the number of chromosomes in a set is even, i.e. those forms giving rise to tetrasomic, hexasomic, etc. inheritance. The emphasis has been placed on elucidating the inheritance of those species in which "... organisms containing sets of four or six homologous loci are reproduced normally by means of diploid or triploid gametes" (Fisher, 1947). Lythrum salicaria is an example of a species normally exhibiting tetrasomic inheritance in which linkage has been investigated (Fisher, 1949).

Earlier studies of linkage in autotetraploids were made by Sömme (1930), De Winton and Haldane (1931), and Sansome (1933). However, the theory of linkage in tetrasomic inheritance was not developed sufficiently at this time to make possible more than approximate estimates of recombination frequencies.

In the present study, application of the general theory developed by Fisher will be made to linkage in trisomic inheritance.

When the number of chromosomes per set is odd, as in trisomic inheritance, meiosis results in at least two classes of gametes, each having different chromosome numbers for a given chromosome set. This usually results in considerable sterility due to genic unbalance in non-homologous chromosomes, and in general, to a lack of stability as a normal mechanism of chromosome transmission. Consequently, trisomic inheritance does not occur as a normal inheritance mechanism.

However, organisms having some or all of their chromosomes in 
sets of three have been synthesised and their inheritance studied. These investigations are valuable because they contribute information which is not obtainable in cases of disomic inheritance. Triploid females have been used in linkage studies involving Drosophila melanogaster (Bridges and Anderson, 1925, and Redfield, 1930 and 1932), and primary trisomics (designated hereafter as trisomics) have been employed in linkage studies of maize (Rhoades, 1933) and in tomatoes (Lesley, 1937).

The term trisomic is used to designate $2 n+1$ chromosomal types in which the chromosomes in one set are in triplicate and in all other sets are in duplicate. Such trisomics are fertile and readily usable in genetic studies. Consistent with the above terminology are the terms monosomic and disomic which we shall use to designate organisms or gametes having one and two chromosomes, respectively, in the given chromosome set.

A trisomic organism produces monosomic and disomic gametes. A complete genetic analysis involves the identification of both gametic series. A single back-cross of the trisomic parent to a completely recessive disomic genotype is all that is necessary to determine the genetic constitution of the monosomic gametes. However, an additional back-cross of the trisomic progeny to the recessive disomic parent is necessary to identify completely the disomic gametes of the original trisomic parent.

Monosomic and disomic gametes can be independently classified into different modes of origin. The frequencies of the modes of gamete origin can be used to estimate the double reduction frequency associated with each locus and the appropriate recombination frequencies. In order that these estimates be unbiased we must assume random disjunction of the chromosomes at meiosis. This assumption will be considered in greater detail in the discussion.

In the following sections we shall consider : (i) the enumeration and classification of trisomic genotypes, (ii) the enumeration and classification of gametes, (iii) the construction of gametic matrices and the estimation of double reduction and recombination frequencies, and (iv) a numerical example.

\section{ENUMERATION AND CLASSIFICATION OF TRISOMIC GENOTYPES}

\section{(a) Numbers of different possible genotypes}

The problem is to compute the number of different genotypes generated by exactly $r$ alleles at the first locus, $s$ alleles at the second locus, etc. To illustrate how this may be done let us consider genotypes involving only two linked loci.

With $\rho$ different alleles at one locus and $\sigma$ different alleles at the other locus there are $\rho \sigma$ different chromosomal types. 
The number of selections of three chromosomes is given by

$$
\frac{\rho \sigma(\rho \sigma+\mathrm{I})(\rho \sigma+2)}{3 !} \text {. }
$$

By substituting the integers I, 2 and 3 for $\rho$ and $\sigma$, the number of genotypes having $\rho$ or fewer different alleles at one locus and $\sigma$ or fewer different alleles at the other locus is obtained. These numbers are given in table $\mathrm{I}$.

\section{TABLE I}

Number of genotypes having $\rho$ or fewer different alleles at one locus and $\sigma$ or fewer alleles at the other locus

\begin{tabular}{l|rrr} 
I & $\overbrace{2}$ & 3 \\
\hline & I & 4 & I0 \\
3 & 4 & 20 & 56 \\
I0 & 56 & 165
\end{tabular}

The number of genotypes having exactly $r$. different alleles at one locus and exactly $s$ at the other can be obtained by operating successively on rows and columns of table I with

$$
\Delta_{\rho}^{r} \Delta_{\sigma}^{s} \frac{\rho \sigma(\rho \sigma+1)(\rho \sigma+2)}{3 !}(\rho=0, \sigma=0) .
$$

The resulting numbers are given in table 2 .

TABLE 2

Number of genotypes having exactly $\mathbf{r}$ different alleles at one locus and $\mathrm{s}$ alleles at the other

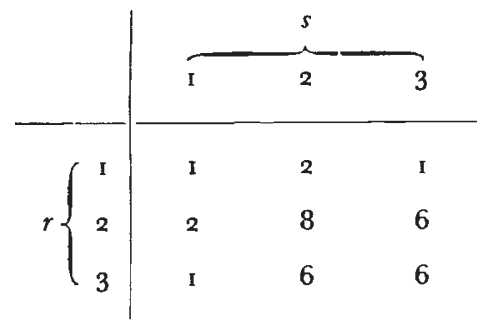

The above procedure can be extended. However, in the general case the enumeration of isomorphic sets rather than individual genotypes is. of primary interest. Therefore we shall defer a generalisation of the enumeration problem until the classification of genotypes into isomorphic sets has been made clear. 
(b) Classification of trisomic genotypes

Trisomic genotypes involving one, two, or three different alleles at a single locus can be associated with the partitions of the number three as follows :

\begin{tabular}{|c|c|c|}
\hline $\begin{array}{c}\text { Type } \\
\text { Genetic formula }\end{array}$ & Partition & Name \\
\hline $\left.\begin{array}{l}a_{1} a_{1} a_{1} \\
a_{1} a_{1} a_{2} \\
a_{1} a_{2} a_{2} \\
a_{1} a_{2} a_{3}\end{array}\right\}$ & $\begin{array}{l}(3) \\
(21) \\
\left(1^{3}\right)\end{array}$ & $\begin{array}{l}\text { Homogenic } \\
\text { Digenic }\left\{\begin{array}{l}\left(\text { duplex for } a_{1}\right) \\
\left(\text { simplex for } a_{1}\right)\end{array}\right. \\
\text { Trigenic }\end{array}$ \\
\hline
\end{tabular}

When two loci are involved, genotypes can be associated with bipartitions of the number three, in which the rows represent the alleles at one locus and the columns represent the alleles at the other locus. Thus, for the genotype $\left(a_{1} b_{1}\right)\left(a_{2} b_{2}\right)\left(a_{3} b_{3}\right)$ the associated bipartition is

\begin{tabular}{l|ccc|c} 
& $b_{1}$ & $b_{2}$ & $b_{3}$ & \\
\hline$a_{1}$ & $\mathrm{I}$ & $\cdot$ & $\cdot$ & \\
$a_{2}$ & $\cdot$ & $\mathrm{I}$ & $\cdot$ & $\left(\mathrm{I}^{3}\right)$ \\
$a_{3}$ & $\cdot$ & $\cdot$ & $\mathrm{I}$ & \\
\hline & & $\left(\mathrm{r}^{3}\right)$ & &
\end{tabular}

Genotypes may be classified into isomorphic sets such that isomorphic genotypes are those which can be derived one from the other by permutation of genes at the same locus.

Experimentally, classification of genotypes into isomorphic sets is important. Most genotypes yield gametic matrices which are deficient in certain respects. Genotypes in the same isomorphic set have equivalent gametic matrices and, therefore, use of different isomorphic genotypes will not alter the elements of deficiency. However, genotypes in different isomorphic sets have different gametic matrices and use of non-isomorphic genotypes may reduce the elements of deficiency.

Isomorphic sets can be related by permutation of loci. Thus, conjugate pairs of sets are those in which one set can be derived from the other by permutation of loci, and a self-conjugate set is one which is transformed into itself by this operation.

To illustrate the classification of genotypes, let us consider those genotypes which are digenic or trigenic at each of two loci. A detailed list is given in table 3 . 
The eight genotypes digenic at both loci can be classified into two isomorphic, self-conjugate sets of four genotypes each. The six genotypes digenic at " $a$ " locus and trigenic at " $b$ " locus constitute

TABLE 3

Classification of genotypes which are digenic or trigenic at each of two loci

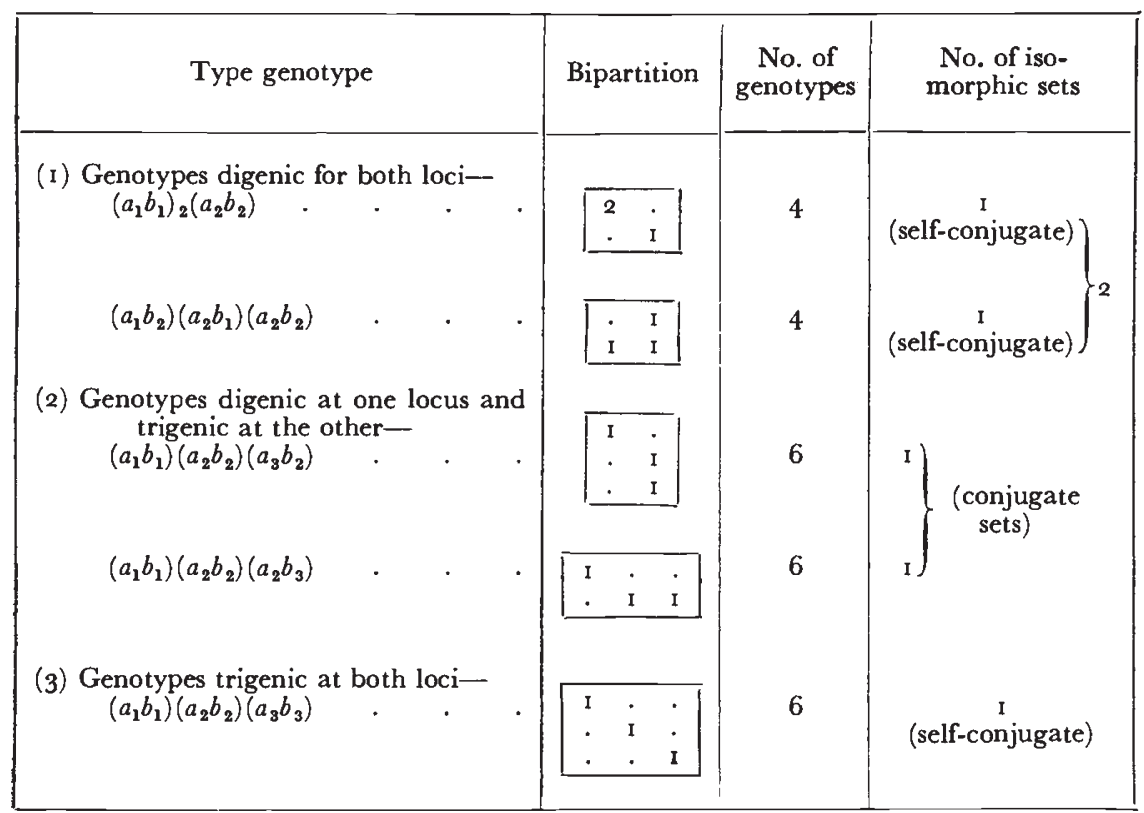

TABLE 4

Number of isomorphic sets of genotypes having exactly $\mathrm{r}$ different alleles at one locus and $\mathrm{s}$ at the other

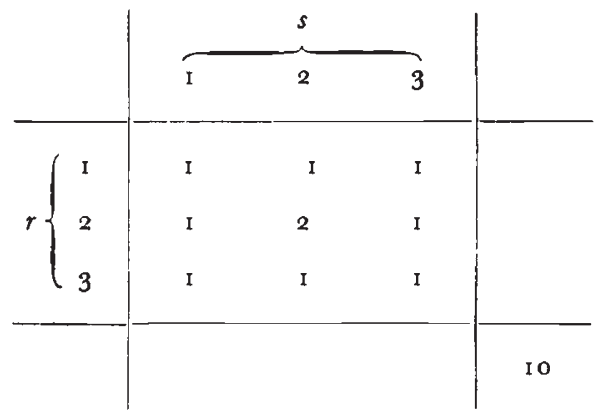

one isomorphic set. This set is conjugate to the set of six genotypes trigenic at the "a" locus and digenic at the "b" locus. The genotypes trigenic at both loci constitute a self-conjugate set. Thus the genotypes involving two loci and having exactly $r$ alleles at one locus and $s$ alleles at the second, as given in table 2, can be classified into isomorphic sets, the numbers of which are given in table 4 . 
Adapting the enumeration procedure given by Fisher (1950) to trisomics we find that the numbers of isomorphic sets for various classes of genotypes can be enumerated for any number, $l$ say, of loci by the following formulæ:

Genotypes digenic for all loci,

$$
\mathrm{A}=\frac{1}{2}\left(\mathrm{I}+3^{l-1}\right) ;
$$

Genotypes digenic and/or trigenic,

All genotypes,

$$
\mathrm{B}=\frac{1}{6}\left(2+3 \cdot 2^{l}+4^{l}\right) ;
$$

$$
\mathrm{C}=\frac{1}{6}\left(2 \cdot 2^{l}+3 \cdot 3^{l}+5^{l}\right) .
$$

\begin{tabular}{|c|c|c|c|}
\hline$l$ & A & B & $\mathbf{C}$ \\
\hline I & I & 2 & 3 \\
\hline 2 & 2 & 5 & 10 \\
\hline 3 & 5 & 15 & 37 \\
\hline 4 & 14 & $5 \mathrm{I}$ & 150 \\
\hline 5 & 41 & 187 & 653 \\
\hline 6 & 122 & 715 & 2990 \\
\hline
\end{tabular}

Using these formulæ the following numbers of isomorphic sets are found for $l$ up to six :

\section{ENUMERATION AND CLASSIFICATION OF GAMETES}

Trisomic genotypes give rise to monosomic and disomic gametes. We shall consider each class separately. Within each class the gametes can be grouped according to their mode of origin. Gametes are said to belong to the same mode of gamete origin if they can be derived one from another by permutation of chromosomes. Since a set of three chromosomes is involved, a symmetric permutation group of degree three (denoted $\mathrm{P}_{3}$ ) can be used to classify the gametes into their respective modes.

\section{(a) Monosomic gametes}

(i) Single locus. The number of different gametic types is obviously equal to the number of different alleles in the parent genotype. The expected gametic ratio is the same as the ratio of alleles in the parent genotype : i.e. the genotype $a_{1} a_{1} a_{2}$ gives rise to the expected gametic ratio of $2\left(a_{1}\right): I\left(a_{2}\right)$. There is only one mode of gamete formation.

(ii) Two linked loci. With exactly $r$ different alleles at one locus and $s$ different alleles at the other, there are $r s$ different chromosomal combinations which in turn are equivalent to the monosomic gametic genotypes. These gametes can be classified into different modes by use of the permutation group $\mathrm{P}_{3}$.

For example, if the genotype is trigenic for each locus, i.e. $\left(a_{1} b_{1}\right)\left(a_{2} b_{2}\right)\left(a_{3} b_{3}\right)$, nine different monosomic gametic types may be 
produced. These are classified into two modes of gamete formation as follows :

\begin{tabular}{|c|c|c|}
\hline Permutation & Mode I & Mode 2 \\
\hline & & \\
\hline I & $a_{1} b_{1}$ & $a_{1} b_{2}$ \\
$(\mathrm{I} 2)$ & $a_{2} b_{2}$ & $a_{2} b_{1}$ \\
$(\mathrm{I} 3)$ & $a_{3} b_{3}$ & $a_{3} b_{2}$ \\
$(23)$ & $a_{1} b_{1}$ & $a_{1} b_{3}$ \\
$(\mathrm{I} 23)$ & $a_{3} b_{3}$ & $a_{3} b_{1}$ \\
$(\mathrm{I} 32)$ & $a_{2} b_{2}$ & $a_{2} b_{3}$ \\
\hline
\end{tabular}

It is clear that mode $I$ represents non-recombinant and mode 2 represents recombinant chromosomal (gametic) types.

(iii) Three linked loci. Assume that the loci are in the linear order $a-b-c$ and that the chromosomal segments between loci " $a$ " and " $b$ " and between " $b$ " and " $c$ " are designated regions $I$ and 2, respectively. A triply "trigenic genotype may produce 27 different possible types of gametes, which can be classified into five gametic

TABLE 5

Classification of monosomic gametes from the genotype $\left(\mathrm{a}_{1} \mathrm{~b}_{1} \mathrm{c}_{1}\right)\left(\mathrm{a}_{2} \mathrm{~b}_{2} \mathrm{c}_{2}\right)\left(\mathrm{a}_{3} \mathrm{~b}_{3} \mathrm{c}_{3}\right)$ into five gametic modes

\begin{tabular}{|c|c|c|c|}
\hline Mode & $\begin{array}{l}\text { Gamete } \\
\text { type }\end{array}$ & $\begin{array}{c}\text { No. of } \\
\text { gametes }\end{array}$ & Genetic interpretation \\
\hline $\begin{array}{l}1 \\
2 \\
3 \\
4\end{array}$ & $\begin{array}{l}a_{1} b_{1} c_{1} \\
a_{1} b_{2} c_{2} \\
a_{1} b_{1} c_{2} \\
a_{1} b_{2} c_{1} \\
a_{1} b_{2} c_{3}\end{array}$ & $\begin{array}{l}3 \\
6 \\
6 \\
6\end{array}$ & $\begin{array}{l}\text { Non-recombinant } \\
\text { Recombination in region I only } \\
\text { Recombination in region } 2 \text { only } \\
\text { Simultaneous recombination in regions I } \\
\text { and } 2 \text { involving two chromosomes (re- } \\
\text { current) } \\
\text { Simultaneous recombination in regions I } \\
\text { and } 2 \text { involving three chromosomes (pro- } \\
\text { gressive) }\end{array}$ \\
\hline
\end{tabular}

modes. This classification together with the genetic interpretation associated with each mode is given in table 5 .

(iv) Four linked loci. With four linked loci in the linear order $a-b-c-d$ there are 8I different possible gametic types from the genotype $\left(a_{1} b_{1} c_{1} d_{1}\right)\left(a_{2} b_{2} c_{2} d_{2}\right)\left(a_{3} b_{3} c_{3} d_{3}\right)$, which can be classified into 14 modes. This classification together with the genetic interpretation associated with each mode is given in table 6 .

In general, the number of modes of gamete formation for any given number, $l$ say, of loci is given by the formula

$$
\mathrm{D}=\frac{1}{2}\left(\mathrm{I}+3^{l-1}\right) .
$$

This formula is the same as that enumerating the number of isomorphic sets of genotypes which are digenic for all loci. 


\section{(b) Disomic gametes}

(i) Single locus. A trisomic genotype having three different genes at a given locus is capable of producing six different disomic gametic types, namely, $a_{1} a_{1}, a_{2} a_{2}, a_{3} a_{3}, a_{1} a_{2}, a_{1} a_{3}$, and $a_{2} a_{3}$. The " homozygous" gametes, resulting from double reduction, constitute one mode, and the "heterozygous" gametes constitute the other.

\section{TABLE 6}

Classification of monosomic gametes from the genotype $\left(\mathrm{a}_{1} \mathrm{~b}_{1} \mathrm{c}_{1} \mathrm{~d}_{1}\right)\left(\mathrm{a}_{2} \mathrm{~b}_{2} \mathrm{c}_{2} \mathrm{~d}_{2}\right) \quad\left(\mathrm{a}_{3} \mathrm{~b}_{3} \mathrm{c}_{3} \mathrm{~d}_{3}\right)$ into 14 gametic modes

\begin{tabular}{|c|c|c|c|}
\hline Mode & $\begin{array}{l}\text { Gamete } \\
\text { type }\end{array}$ & $\begin{array}{l}\text { No. of } \\
\text { gametes }\end{array}$ & Genetic interpretation \\
\hline 1 & $a_{1} b_{1} c_{1} d_{1}$ & 3 & Non-recombinant \\
\hline 2 & $a_{1} b_{2} c_{2} d_{2}$ & 6 & Recombination in region 1 only \\
\hline 3 & $a_{1} b_{1} c_{2} d_{2}$ & 6 & Recombination in region 2 only \\
\hline 4 & $a_{1} b_{1} c_{1} d_{2}$ & 6 & Recombination in region 3 only \\
\hline 5 & $a_{1} b_{2} c_{1} d_{1}$ & 6 & $\begin{array}{l}\text { Recombination in regions } 1 \text { and } 2 \text { ( } 2 \text { chromo- } \\
\text { somes involved) }\end{array}$ \\
\hline 6 & $a_{1} b_{2} c_{3} d_{3}$ & 6 & $\begin{array}{l}\text { Recombination in regions } 1 \text { and } 2 \text { ( } 3 \text { chromo- } \\
\text { somes involved) }\end{array}$ \\
\hline 7 & $a_{1} b_{2} c_{2} d_{1}$ & 6 & $\begin{array}{l}\text { Recombination in regions } \mathrm{I} \text { and } 3 \text { ( } 2 \text { chromo- } \\
\text { somes involved) }\end{array}$ \\
\hline 8 & $a_{1} b_{2} c_{2} d_{3}$ & 6 & $\begin{array}{l}\text { Recombination in regions } 1 \text { and } 3 \text { ( } 3 \text { chromo- } \\
\text { somes involved) }\end{array}$ \\
\hline 9 & $a_{1} b_{1} c_{2} d_{1}$ & 6 & $\begin{array}{l}\text { Recombination in regions } 2 \text { and } 3 \text { ( } 2 \text { chromo- } \\
\text { somes involved) }\end{array}$ \\
\hline 10 & $a_{1} b_{1} c_{2} d_{3}$ & 6 & $\begin{array}{l}\text { Recombination in regions } 2 \text { and } 3 \text { ( } 3 \text { chromo- } \\
\text { somes involved) }\end{array}$ \\
\hline I I & $a_{1} b_{2} c_{1} d_{2}$ & 6 & $\begin{array}{l}\text { Recombination in regions } 1,2 \text { and } 3(2 \\
\text { chromosomes involved) }\end{array}$ \\
\hline I 2 & $a_{1} b_{2} c_{1} d_{3}$ & 6 & $\begin{array}{l}\text { Recombination in regions } 1,2 \text { and } 3 \text { ( } 3 \\
\text { chromosomes involved) }\end{array}$ \\
\hline 13 & $a_{1} b_{2} c_{3} d_{1}$ & 6 & $\begin{array}{l}\text { Recombination in regions } 1,2 \text { and } 3 \text { (3 } \\
\text { chromosomes involved) }\end{array}$ \\
\hline I 4 & $a_{1} b_{2} c_{3} d_{2}$ & 6 & $\begin{array}{l}\text { Recombination in regions } 1,2 \text { and } 3 \text { (3 } \\
\text { chromosomes involved) }\end{array}$ \\
\hline
\end{tabular}

(ii) Two linked loci. If at two linked loci there are $r$ different genes at one locus and $s$ different genes at the other, there are $r s$ different chromosomal types. These may give rise to a possible number of $\frac{r s(r s+1)}{2}$ different disomic gametes

For example, the genotype $\left(a_{1} b_{1}\right)\left(a_{2} b_{2}\right)\left(a_{3} b_{3}\right)$ yields nine different chromosomal types which, taken in pairs, form 45 different possible disomic gametes. These can be classified into ro gametic modes by the permutation group, $\mathbf{P}_{3}$. Table 7 lists the modes together with the gametic information which can be obtained from them. These modes have been numbered so as to correspond to the tetrasomic modes (Fisher, I947), except that, since tetrasomic mode six does not occur in trisomics, the trisomic mode six corresponds to tetrasomic mode 7 , etc. 
In general, the number of modes of gamete formation for any given number, $l$ say, of loci is given by the formula

$$
\mathrm{E}=\frac{1}{12}\left(9^{l}+4 \cdot 3^{l}+3\right)
$$

which yields the following values for $l$ up to 6 :

\begin{tabular}{ccccccc}
$l$ & $\mathrm{I}$ & 2 & 3 & 4 & 5 & 6 \\
\hline $\mathrm{E}$ & 2 & IO & 70 & 574 & 5002 & $4453^{\circ}$
\end{tabular}

TABLE 7

Classification of disomic gametes from the genotype $\left(\mathrm{a}_{1} \mathrm{~b}_{1}\right)\left(\mathrm{a}_{2} \mathrm{~b}_{2}\right)\left(\mathrm{a}_{3} \mathrm{~b}_{3}\right)$ into 10 gametic modes

\begin{tabular}{|c|c|c|c|c|c|}
\hline \multirow{2}{*}{ Mode } & \multirow{2}{*}{$\begin{array}{l}\text { Gamete } \\
\text { type }\end{array}$} & \multirow{2}{*}{$\begin{array}{l}\text { No. of } \\
\text { gametes }\end{array}$} & \multirow{2}{*}{$\begin{array}{l}\text { Recombinant } \\
\text { chromosomes }\end{array}$} & \multicolumn{2}{|c|}{ Double reduction at } \\
\hline & & & & " $a$ " locus & " $b$ " locus \\
\hline $\begin{array}{r}1 \\
2 \\
3 \\
4 \\
5 \\
6 \\
7 \\
8 \\
9 \\
9\end{array}$ & $\begin{array}{l}\left(a_{1} b_{1}\right)\left(a_{2} b_{2}\right) \\
\left(a_{1} b_{1}\right)\left(a_{1} b_{1}\right) \\
\left(a_{1} b_{1}\right)\left(a_{2} b_{3}\right) \\
\left(a_{1} b_{1}\right)\left(a_{1} b_{2}\right) \\
\left(a_{1} b_{1}\right)\left(a_{2} b_{1}\right) \\
\left(a_{2} b_{1}\right)\left(a_{3} b_{1}\right) \\
\left(a_{1} b_{2}\right)\left(a_{1} b_{3}\right) \\
\left(a_{1} b_{2}\right)\left(a_{2} b_{3}\right) \\
\left(a_{1} b_{2}\right)\left(a_{1} b_{2}\right) \\
\left(a_{1} b_{2}\right)\left(a_{2} b_{1}\right)\end{array}$ & $\begin{array}{l}3 \\
3 \\
6 \\
6 \\
6 \\
3 \\
3 \\
6 \\
6 \\
3\end{array}$ & $\begin{array}{l}\text { o } \\
0 \\
\frac{1}{2} \\
\frac{1}{2} \\
\frac{1}{2} \\
\text { I } \\
\text { I } \\
\text { I } \\
\text { I } \\
\text { I }\end{array}$ & $\begin{array}{l} \pm \\
\pm \\
\pm \\
\pm \\
\pm \\
\pm \\
\pm\end{array}$ & $\begin{array}{l}\overline{+} \\
\overline{-} \\
\bar{t} \\
\pm \\
\pm \\
\pm \\
\pm\end{array}$ \\
\hline
\end{tabular}

\section{GAMETIC MATRICES AND THE ESTIMATION OF GENETIC PARAMETERS}

We have seen that a trisomic genotype gives rise to monosomic and disomic gametes. These two classes of gametes can be treated independently. Within each class the gametes are assigned to modes of gamete formation. We are concerned with the frequencies of these modes of gamete formation since it is clear that recombination and double reduction parameters are functions of the gametic mode frequencies. For example, consider genotypes at two loci. If all gametes are identifiable it is obvious that

(a) for monosomic gametes

$$
y_{a b}=f_{2} \text {, and }
$$

(b) for disomic gametes

$$
\begin{aligned}
y_{a b}= & \frac{1}{2}\left(f_{3}+f_{4}+f_{5}\right)+f_{6}+f_{7}+f_{8}+f_{9}+f_{10} \\
& \alpha_{a}=f_{2}+f_{4}+f_{7}+f_{9} \\
& \alpha_{b}=f_{2}+f_{5}+f_{6}+f_{9},
\end{aligned}
$$

where $y_{a b}$ is the recombination frequency for the chromosomal segment between the " $a$ " and " $b$ " loci, $f_{i}$ is the frequency of the $i^{t h}$ mode, and $\alpha_{j}$ is the double reduction frequency for the $j^{\text {th }}$ locus. 
The estimation of genetic parameters from either class of gametes is briefly outlined as follows :

Denote the frequencies of gametic modes by the row vector $\mathbf{F}=\left(f_{1}, f_{2}, \ldots ..\right)$, and the observed gametic numbers by the vector $\mathrm{A}=\left(a_{1}, a_{2}, \ldots ..\right)$, where the total number of gametes identified is $\mathrm{N}=\sum_{i} a_{i}$. A gametic matrix $\left\{g_{i j}\right\}$ is defined in which the rows correspond to modes and the columns correspond to gametic genotypes in such a way that the elements in the $i^{t h}$ row are the expected gametic frequencies for the $i^{t h}$ mode. The expected numbers for the different gametes.are given by the matrix equation $\mathbf{F} \cdot \mathbf{G}=\mathbf{M}=\left\{m_{k}\right\}$, where $\mathbf{G}=\mathbf{N}\left\{g_{i j}\right\}$.

If the rank of $\mathrm{G}$ is equal to the number of different modes, maximum likelihood estimates of the frequencies $F$ are possible. This is usually the case for those monosomic gametic matrices of interest. However, it is usually not the case for the disomic gametic matrices.

To examine more closely the situation with disomic gametic matrices, let us consider those matrices arising from genotypes involving genes at two loci.

If the rank of $\mathrm{G}$ is 10 , it is possible to estimate all $f_{i}$ from the experimental data. However, this is true only for the genotype $\left(a_{1} b_{1}\right)\left(a_{2} b_{2}\right)\left(a_{3} b_{3}\right)$.

If the rank of $\mathrm{G}$ is less than $10\{r$ say, where $r<\mathrm{Io}\}$ then a deficiency matrix, $\mathrm{D}$, of rank $(10-r)$ is associated with $\mathrm{G}$ such that

$$
\mathrm{D}_{(10-r) \times 10} \cdot \mathrm{G}_{10 \times n}=\mathrm{O}_{(10-r) \times n},
$$

where $n$ is the number of different gametes. To determine estimable functions of $f_{i}$ we define a matrix $\mathrm{T}$ of rank $r$ such that

$$
\mathrm{D}_{(10-r) \times 10} \cdot \mathrm{T}_{10 \times r}=\mathrm{O}_{(10-r) \times r}
$$

The estimable functions are then defined as $\mathrm{U}_{1 \times r}=\mathrm{F}_{1 \times 10} \cdot \mathrm{T}_{10 \times r}$.

A new gametic matrix $\mathrm{G}^{*}=\mathbf{N}\left\{g_{i j}^{*}\right\}$ is constructed such that $\mathrm{U}_{1 \times r} \cdot \mathrm{G}^{*}{ }_{r \times n}=\mathrm{M}_{1 \times n}$, where $\mathrm{M}$ is the row vector of expected gametic numbers. Then, given the observed gametic frequencies $\mathrm{A}=\left(a_{1}, a_{2}, \ldots . ..\right)$, it is possible to calculate the maximum likelihood estimates $\hat{U}_{1 \times r}$ (see Fisher, 1947). In all cases which will be discussed, it is possible to estimate recombination and double reduction parameters by use of $\hat{U}_{1 \times r}$.

In those genotypes trigenic for all loci, each gametic type is produced by one, and only one, mode of gamete formation. In this case the estimation of mode frequencies is extremely simple in that the $i^{t h}$ mode frequency is estimated as the summation of frequencies of all observable gametic types due to the $i^{\text {th }}$ mode of origin.

However, with all other genotypes certain gametic types may result from two or more different gametic modes, and a more complicated procedure is necessary to obtain maximum likelihood estimates. This procedure is outlined and illustrated in detail by Fisher (1947) and, 
therefore, will not be given here. Suffice it to say that the procedure is an iterative one in which it is necessary to invert a square information matrix of dimensions $n \times n$, where $n$ is one less than the rank of the gametic matrix involved. Because of computational difficulties, the size of the gametic matrix which can be inverted is limited. For this reason we shall give examples of monosomic gametic matrices for genotypes involving up to four loci, and examples of disomic gametic matrices for genotypes involving only two loci.

Methods by means of which a considerable number of loci may be included in a given study are suggested in the discussion.

\section{(a) Monosomic gametic matrices}

(i) Single locus. Trisomic genotypes involving alleles at a single locus yield monosomic gametes all of which can be classified into a single mode of gamete formation.

Data arising from monosomic gametes may be utilised for making "goodness of fit" tests. In this case the observed numbers of different disomic backcross progeny are compared with expected numbers based upon the frequencies of the alleles in the parental genotype. Discrepancies are probably due to viability differences associated directly with the alleles or to closely linked genes having lowered viability effects.

(ii) Two linked loci. The genotype $\left(a_{1} b_{1}\right)\left(a_{2} b_{2}\right)\left(a_{3} b_{3}\right)$ gives rise to the monosomic gametic matrix given in table 8 .

TABLE 8

Monosomic gametic matrix for the genotype $\left(\mathrm{a}_{1} \mathrm{~b}_{1}\right)\left(\mathrm{a}_{\mathbf{2}} \mathrm{b}_{2}\right)\left(\mathrm{a}_{\mathbf{3}} \mathrm{b}_{3}\right)$

\begin{tabular}{|c|c|c|c|c|c|c|c|c|c|}
\hline \multirow{2}{*}{ Mode } & \multicolumn{8}{|c|}{ Gametes } \\
\cline { 2 - 7 } & $a_{1} b_{1}$ & $a_{2} b_{2}$ & $a_{3} b_{3}$ & $a_{1} b_{2}$ & $a_{1} b_{3}$ & $a_{2} b_{3}$ & $a_{2} b_{1}$ & $a_{3} b_{1}$ & $a_{3} b_{2}$ \\
\hline 1 & $\frac{1}{3}$ & $\frac{1}{3}$ & $\frac{1}{3}$ & $\ldots$ & $\ldots$ & $\ldots$ & $\ldots$ & $\ldots$ & $\ldots$ \\
2 & $\ldots$ & $\ldots$ & $\ldots$ & $\frac{1}{6}$ & $\frac{1}{8}$ & $\frac{1}{6}$ & $\frac{1}{6}$ & $\frac{1}{8}$ & $\frac{1}{8}$ \\
\hline
\end{tabular}

Corresponding gametic matrices may be formed for other genotypes. Of particular interest are the gametic matrices for the genotypes $\left(a_{1} b_{1}\right)_{2}\left(a_{2} b_{2}\right)$ and $\left(a_{1} b_{1}\right)\left(a_{1} b_{2}\right)\left(a_{2} b_{1}\right)$. These are given in tables 9 and 10. Both of these matrices are of rank two and, therefore, gametic mode frequencies can be estimated.

(iii) Three linked loci. The monosomic gametic matrix for the genotype $\left(a_{1} b_{1} c_{1}\right)\left(a_{2} b_{2} c_{2}\right)\left(a_{3} b_{3} c_{3}\right)$ consists of five rows corresponding to the five modes and 27 columns corresponding to the 27 different possible gametes. 
The entries in the matrix may be described as follows :

Mode I : frequency of $\frac{1}{3}$ for gametes of type $a_{1} b_{1} c_{1}$ and zero elsewhere ;

Mode 2: frequency of $\frac{1}{8}$ for gametes of type $a_{1} b_{2} c_{2}$ and zero elsewhere ;

Mode 3: frequency of $\frac{1}{6}$ for gametes of type $a_{1} b_{1} c_{2}$ and zero elsewhere ;

Mode 4: frequency of $\frac{1}{6}$ for gametes of type $a_{1} b_{2} c_{1}$ and zero elsewhere ; and,

Mode 5: frequency of $\frac{1}{6}$ for gametes of type $a_{1} b_{2} c_{3}$ and zero elsewhere.

TABLE 9

Monosomic gametic matrix for the genotype $\left(\mathrm{a}_{1} \mathrm{~b}_{1}\right)_{2}\left(\mathrm{a}_{2} \mathrm{~b}_{2}\right)$

\begin{tabular}{|c|c|c|c|c|}
\hline \multirow{2}{*}{ Mode } & \multicolumn{4}{|c|}{ Gametes } \\
\cline { 2 - 5 } & $a_{1} b_{1}$ & $a_{2} b_{2}$ & $a_{1} b_{2}$ & $a_{2} b_{2}$ \\
\hline 1 & $\frac{2}{3}$ & $\frac{1}{3}$ & $\ldots$ & $\ldots$ \\
2 & $\frac{1}{3}$ & $\ldots$ & $\frac{1}{3}$ & $\frac{1}{3}$ \\
\hline
\end{tabular}

TABLE 10

Monosomic gametic matrix for the genotype $\left(a_{1} b_{1}\right)\left(a_{1} b_{2}\right)\left(a_{2} b_{1}\right)$

\begin{tabular}{|c|c|c|c|c|}
\hline \multirow{2}{*}{ Mode } & \multicolumn{4}{|c|}{ Gametes } \\
\cline { 2 - 4 } & $a_{1} b_{1}$ & $a_{1} b_{2}$ & $a_{2} b_{1}$ & $a_{2} b_{2}$ \\
\hline 1 & $\frac{1}{3}$ & $\frac{1}{3}$ & $\frac{1}{3}$ & $\ldots$ \\
2 & $\frac{3}{6}$ & $\frac{1}{6}$ & $\frac{1}{6}$ & $\frac{1}{6}$ \\
\hline
\end{tabular}

This matrix is of rank five and therefore gametic mode frequencies can be estimated.

Gametic matrices for other genotypes may be easily derived from the one given above. Of particular interest is that for the genotype $\left(a_{2} b_{1} c_{1}\right)\left(a_{1} b_{2} c_{1}\right)\left(a_{1} b_{1} c_{2}\right)$. This matrix, which is set out in table II, is needed for the computational example given in Section V. It is of rank five and, therefore, the mode frequencies can be estimated.

(b) Disomic gametic matrices

(i) Single locus. The gametic matrix for the genotype $a_{1} a_{2} a_{3}$ is given in table 12 . The homozygous gametes $a_{\mathrm{i}} a_{\mathrm{i}}$ arise from a common 
mode of gamete formation and are due to the phenomenon of double reduction.

This matrix is of rank two, and therefore if the gametic types can

TABLE II

Monosomic gametic matrix for the genotype $\left(\mathrm{a}_{2} \mathrm{~b}_{1} \mathrm{c}_{1}\right)\left(\mathrm{a}_{1} \mathrm{~b}_{2} \mathrm{c}_{1}\right)\left(\mathrm{a}_{1} \mathrm{~b}_{2} \mathrm{c}_{2}\right)$

\begin{tabular}{|c|c|c|c|c|c|c|c|c|}
\hline \multirow{2}{*}{ Mode } & \multicolumn{8}{|c|}{ Gametes } \\
\hline & $a_{1} b_{1} c_{1}$ & $a_{1} b_{1} c_{2}$ & $a_{1} b_{2} c_{1}$ & $a_{1} b_{2} c_{2}$ & $a_{2} b_{1} c_{1}$ & $a_{2} b_{2} c_{1}$ & $a_{2} b_{9} \mathfrak{f}_{2}$ & $a_{2} b_{1} c_{2}$ \\
\hline I & & $\frac{1}{3}$ & $\frac{1}{3}$ & ... & 李 & & $\ldots$ & \\
\hline 2 & $\frac{1}{3}$ & $\frac{1}{8}$ & $\frac{1}{6}$ & & 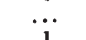 & $\frac{1}{6}$ & $\cdots$ & $\frac{1}{6}$ \\
\hline $\begin{array}{l}3 \\
4\end{array}$ & $\begin{array}{l}\frac{1}{3} \\
\frac{1}{3}\end{array}$ & $\frac{1}{6}$ & f & $\frac{1}{6}$ & $\frac{1}{8}$ & 1 & $\begin{array}{l}\cdots \\
\ldots\end{array}$ & $\frac{1}{6}$ \\
\hline 5 & $\frac{1}{3}$ & $\frac{1}{6}$ & $\frac{1}{6}$ & $\cdots$ & $\frac{1}{6}$ & $\ldots$ & $\frac{1}{6}$ & $\ldots$ \\
\hline
\end{tabular}

TABLE 12

Disomic gametic matrix for the genotype $\mathrm{a}_{1} \mathrm{a}_{2} \mathrm{a}_{3}$

\begin{tabular}{|c|c|c|c|c|c|c|}
\hline \multirow{2}{*}{ Mode } & \multicolumn{6}{|c|}{ Gametes } \\
\hline & $a_{1} a_{1}$ & $a_{2} a_{2}$ & $a_{3} a_{3}$ & $a_{1} a_{2}$ & $a_{1} a_{3}$ & $a_{2} a_{3}$ \\
\hline I & $\frac{1}{b}$ & $\frac{1}{3}$ & $\frac{1}{8}$ & $\ldots$ & $\ldots$ & $\ldots$ \\
\hline 2 & $\ldots$ & $\ldots$ & $\ldots$ & $\frac{1}{3}$ & $\frac{1}{3}$ & $\frac{1}{8}$ \\
\hline
\end{tabular}

TABLE 13

Disomic gametic matrix for the genotype $\mathrm{a}_{1} \mathrm{a}_{1} \mathrm{a}_{2}$

\begin{tabular}{|c|c|c|c|}
\hline \multirow{2}{*}{ Mode } & \multicolumn{3}{|c|}{ Gametes } \\
\cline { 2 - 4 } & $a_{1} a_{1}$ & $a_{2} a_{2}$ & $a_{1} a_{2}$ \\
\hline 1 & $\frac{2}{3}$ & $\frac{1}{3}$ & $\ldots$ \\
2 & $\ldots$ & $\ldots$ & 1 \\
\hline
\end{tabular}

be identified, there is no problem in estimating the mode frequencies and hence the frequency of double reduction.

However, the estimation procedure usually involves digenic types in which one allele is dominant to the other. If $a_{1}$ is dominant to $a_{2}$, the appropriate cross for estimating double reduction frequency is $a_{1} a_{1} a_{2} \times a_{2} a_{2}$. The disomic gametic matrix for $a_{1} a_{1} a_{2}$ is given in table I3, and the corresponding phenotypic matrix associated with 
the backcross progeny is given in table I4. If we let $a$ represent the frequency of double reduction, and if $n$ is the number of observed recessive phenotypes occurring in a total number of $\mathrm{N}$ trisomic progeny, then $\alpha$ is estimated by $\hat{a}=\frac{3^{n}}{\mathrm{~N}}$.

(ii) Genotypes involving two loci. The genotype having three different alleles at each of two linked loci, i.e. $\left(a_{1} b_{1}\right)\left(a_{2} b_{2}\right)\left(a_{3} b_{3}\right)$ has a disomic gametic matrix of 10 rows (each corresponding to a mode of gamete

TABLE 14

Phenotypic matrix for trisomic progeny from the cross $a_{1} a_{1} a_{2} \times a_{2} a_{2}$

\begin{tabular}{|c|c|c|}
\hline \multirow{2}{*}{ Mode } & \multicolumn{2}{|c|}{ Phenotypes } \\
\cline { 2 - 3 } & $\begin{array}{c}\text { recessive } \\
a_{2} a_{2} a_{2}\end{array}$ & $\begin{array}{c}\text { dominant } \\
a_{1}\end{array}$ \\
\hline 1 & $\frac{1}{3}$ & $\frac{2}{3}$ \\
2 & $\ldots$ & 1 \\
\hline
\end{tabular}

formation) and 45 columns (one for each gametic type). The entries, given for each row, may be described as follows :

Mode I : frequency of $\frac{1}{3}$ for gametes of type $\left(a_{1} b_{1}\right)\left(a_{2} b_{2}\right)$ and zero elsewhere.

Mode 2 : frequency of $\frac{1}{3}$ for gametes of type $\left(a_{1} b_{1}\right)\left(a_{1} b_{1}\right)$ and zero elsewhere.

Mode 3 : frequency of $\frac{1}{6}$ for gametes of type $\left(a_{1} b_{1}\right)\left(a_{2} b_{3}\right)$ and zero elsewhere.

Mode $4:$ frequency of $\frac{1}{6}$ for gametes of type $\left(a_{1} b_{1}\right)\left(a_{1} b_{2}\right)$ and zero elsewhere.

Mode 5 : frequency of $\frac{1}{6}$ for gametes of type $\left(a_{1} b_{1}\right)\left(a_{2} b_{1}\right)$ and zero elsewhere.

Mode 6: frequency of $\frac{1}{3}$ for gametes of type $\left(a_{2} b_{1}\right)\left(a_{3} b_{1}\right)$ and zero elsewhere.

Mode 7 : frequency of $\frac{1}{3}$ for gametes of type $\left(a_{1} b_{2}\right)\left(a_{1} b_{3}\right)$ and zero elsewhere.

Mode 8 : frequency of $\frac{1}{6}$ for gametes of type $\left(a_{1} b_{2}\right)\left(a_{2} b_{3}\right)$ and zero elsewhere.

Mode $9:$ frequency of $\frac{1}{6}$ for gametes of type $\left(a_{1} b_{2}\right)\left(a_{1} b_{2}\right)$ and zero elsewhere.

Mode Io: frequency of $\frac{1}{3}$ for gametes of type $\left(a_{1} b_{2}\right)\left(a_{2} b_{1}\right)$ and zero elsewhere.

Since the rank of this matrix is 10, gametic mode frequencies can be estimated. 


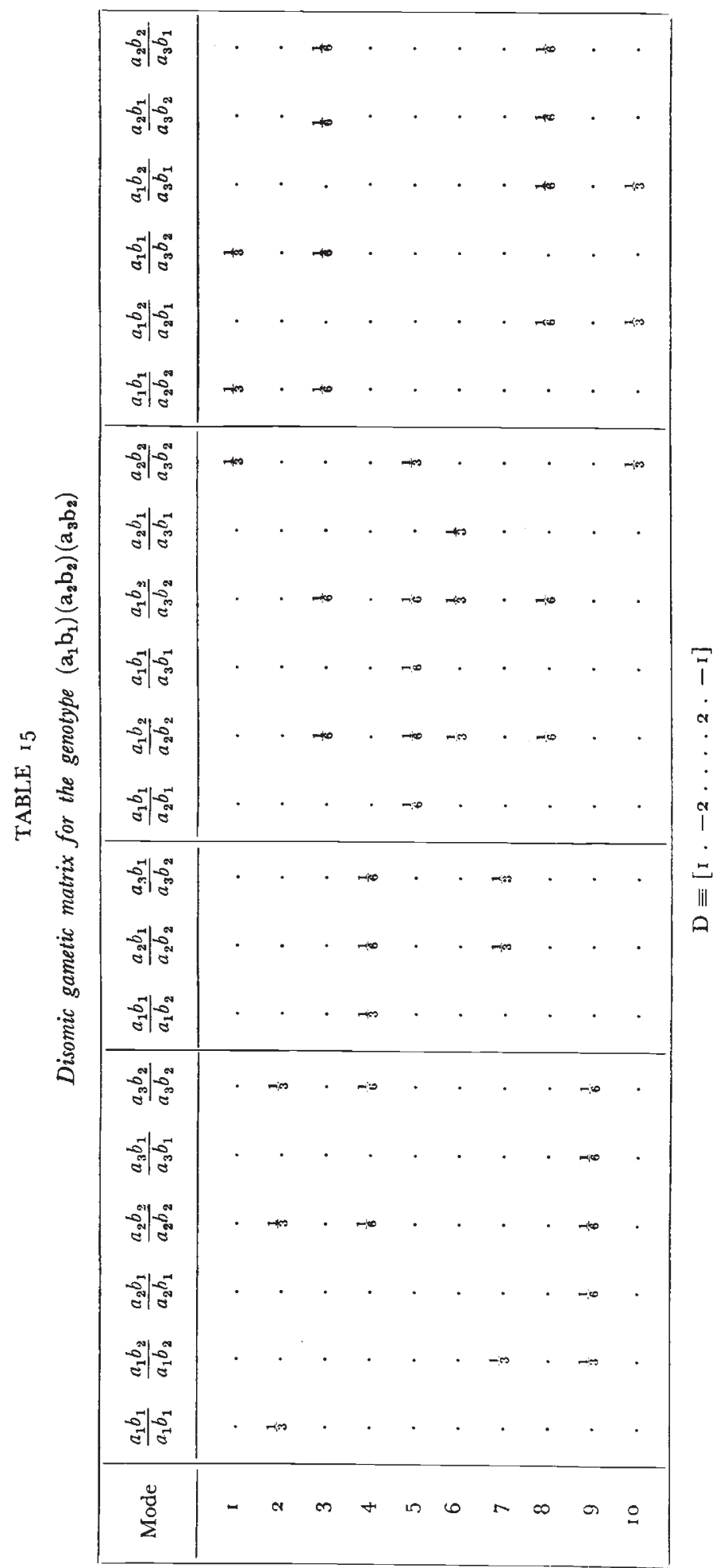


Genotypes digenic at one locus and trigenic at the other yield gametic matrices having the dimensions of Io rows by 2 I columns. Such a matrix for the genotype $\left(a_{1} b_{1}\right)\left(a_{2} b_{2}\right)\left(a_{3} b_{2}\right)$ is given in table I 5 . Since the rank of this matrix is nine there is a deficiency row vector, $D$, associated with it. A set of estimable variables $\mathrm{U}=\left(u_{1} \ldots \ldots u_{9}\right)$ may be defined. The functional relationships of $U_{1 \times 9}$ and $F_{1 \times 10}$ are set out in table ${ }_{1} 6$. The gametic matrix $\mathrm{G}^{*}{ }_{9 \times 21}$ of rank nine, associated with the $U_{1 \times 9}$ variables is given in table I 7 . Maximum likelihood estimates, $\hat{\mathrm{U}}_{1 \times 9}$, can be obtained using the observed gametic numbers $\mathrm{A}=\left(a_{1}, a_{2} \ldots \ldots a_{21}\right)$.

TABLE 16

$A$ set of estimable variables $U_{1 \times 0}$ as functions of the gametic mode frequencies $F_{1 \times 10}$ for the genotype $\left(\mathrm{a}_{1} \mathrm{~b}_{1}\right)\left(\mathrm{a}_{2} \mathrm{~b}_{2}\right)\left(\mathrm{a}_{3} \mathrm{~b}_{2}\right)$

\begin{tabular}{|c|c|c|c|c|c|c|c|c|c|c|}
\hline & $f_{1}$ & $f_{2}$ & $f_{3}$ & $f_{\mathbf{a}}$ & $f_{\mathrm{b}}$ & $f_{\mathrm{s}}$ & $f_{7}$ & $f_{8}$ & $f_{9}$ & $f_{10}$ \\
\hline $\begin{array}{l}u_{1} \\
u_{2} \\
u_{3} \\
u_{4} \\
u_{5} \\
u_{6} \\
u_{7} \\
u_{8} \\
u_{9}\end{array}$ & $\begin{array}{l}\text { I } \\
\vdots \\
\vdots \\
\vdots\end{array}$ & $\begin{array}{l}\text { I } \\
\text { : } \\
\text { : }\end{array}$ & $\begin{array}{l}\frac{1}{2} \\
\frac{1}{2} \\
\frac{1}{2}\end{array}$ & : & : & : & : & $\frac{1}{2}$ & $\begin{array}{l}: \\
: \\
:\end{array}$ & 1 \\
\hline
\end{tabular}

Double reduction and recombination frequencies can be estimated from $\hat{U}$ as follows :

$$
\begin{aligned}
\hat{a}_{a} & =\hat{u}_{2}+\hat{u}_{4}+\hat{u}_{7}+\hat{u}_{9} \\
\hat{a}_{b} & =\hat{u}_{2}+\hat{u}_{5}+\hat{u}_{6}+\hat{u}_{9} \\
\hat{y}_{a b} & =\frac{1}{2}\left(2 \hat{u}_{3}+\hat{u}_{4}+\hat{u}_{5}\right)+\hat{u}_{6}+\hat{u}_{7}+\hat{u}_{8}+\hat{u}_{9} .
\end{aligned}
$$

Genotypes digenic at each of two loci can be classified into two isomorphic sets. It is of interest to examine disomic gametic matrices for at least two non-isomorphic genotypes. We choose the genotypes $\left(a_{1} b_{1}\right)_{2}\left(a_{2} b_{2}\right)$ and $\left(a_{1} b_{1}\right)\left(a_{1} b_{2}\right)\left(a_{2} b_{1}\right)$.

The genotype $\left(a_{1} b_{1}\right)_{2}\left(a_{2} b_{2}\right)$ has a disomic gametic matrix of rank eight and, therefore, an associated deficiency matrix of rank two. These are given in table 18 . The estimable variables $U_{1 \times 8}$ are given in table 19 as functions of $F_{1 \times 10}$. The gametic matrix $G^{*}{ }_{6 \times 10}$ of rank eight associated with the variables $\mathrm{U}_{1 \times 8}$ is given in table 20. Double reduction and recombination estimates are obtained from $\hat{U}$ as follows :

$$
\begin{aligned}
\hat{a}_{a} & =\hat{u}_{2}+\hat{u}_{4}+\hat{u}_{7} \\
\hat{a}_{b} & =\hat{u}_{2}+\hat{u}_{5}+\hat{u}_{6}+\hat{u}_{7} \\
\hat{y}_{a b} & =\frac{1}{2}\left(\hat{u}_{3}+\hat{u}_{4}+\hat{u}_{5}\right)+\hat{u}_{6}+\hat{u}_{7}+\hat{u}_{8} .
\end{aligned}
$$

The disomic gametic matrix of rank eight and its associated deficiency matrix of rank two for the genotype $\left(a_{1} b_{1}\right)\left(a_{1} b_{2}\right)\left(a_{2} b_{1}\right)$ are 


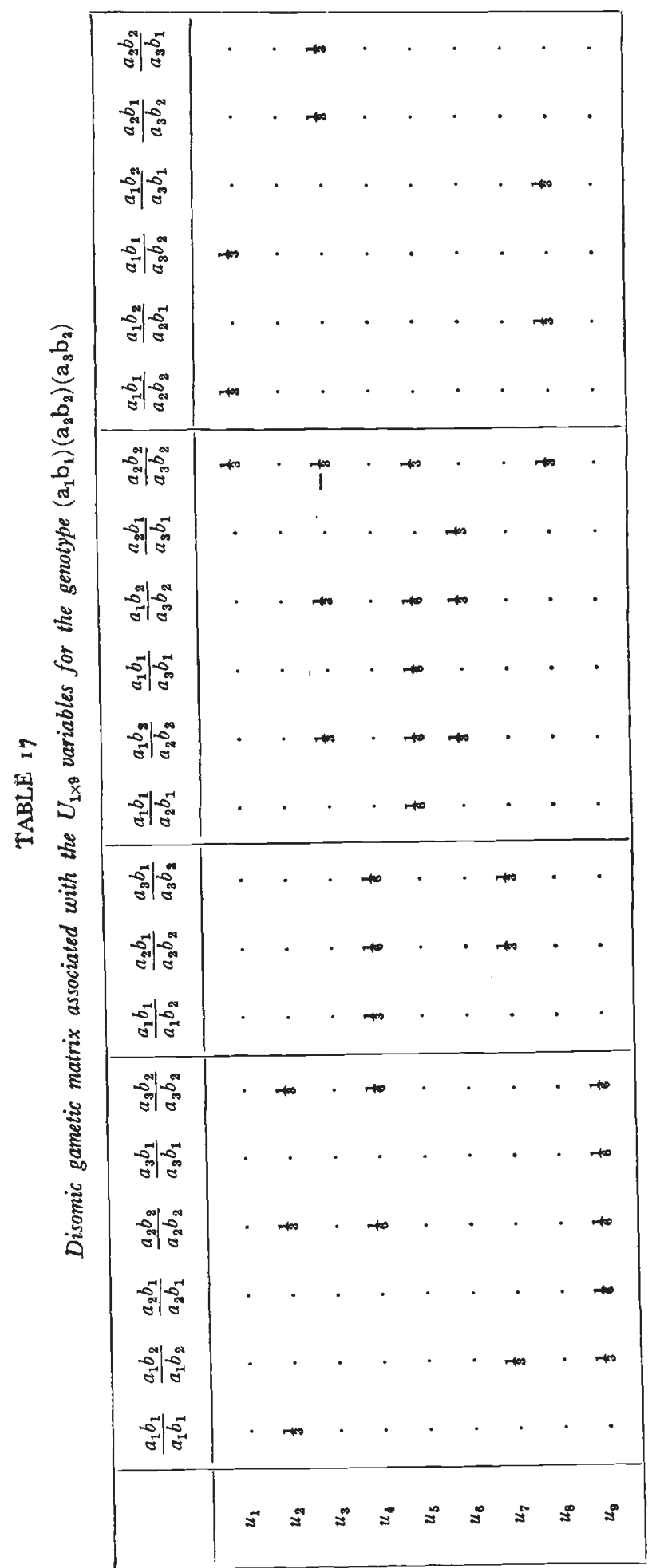


TABLE 18

Disomic gametic matrix for the genotype $\left(\mathrm{a}_{1} \mathrm{~b}_{1}\right)_{2}\left(\mathrm{a}_{2} \mathrm{~b}_{2}\right)$

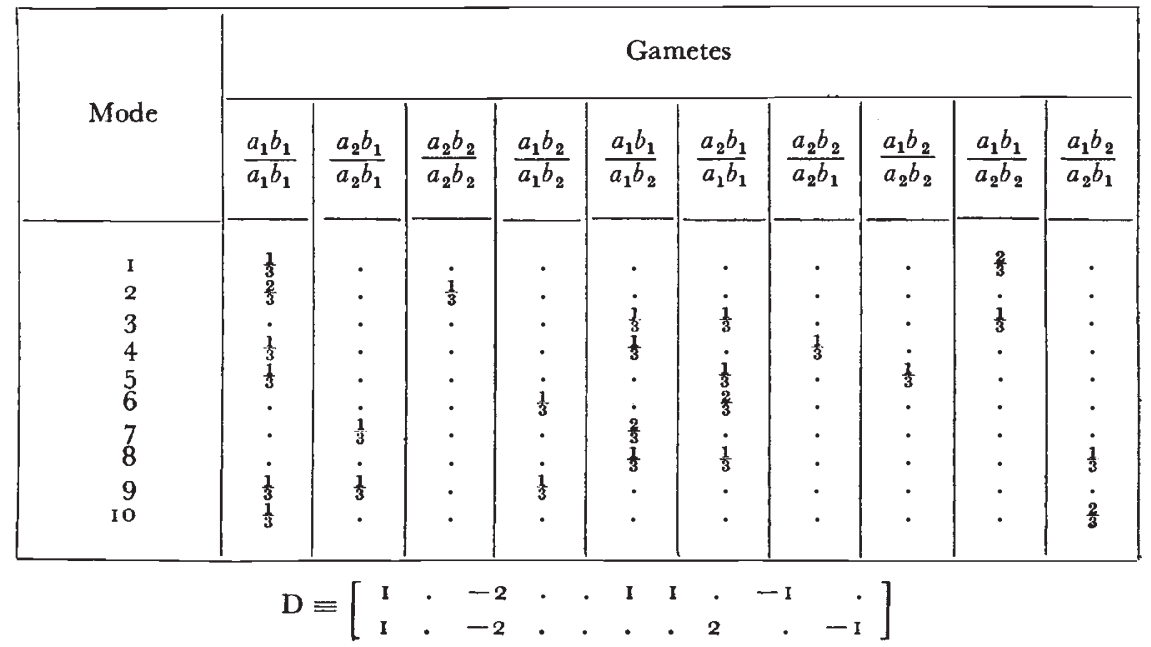

TABLE 19

$A$ set of estimable variables, $U_{1 \times 9}$ as functions of gametic mode frequencies, $F_{1 \times 10}$ for the genotype $\left(\mathrm{a}_{1} \mathrm{~b}_{1}\right)_{2}\left(\mathrm{a}_{2} \mathrm{~b}_{2}\right)$

\begin{tabular}{|c|c|c|c|c|c|c|c|c|c|c|}
\hline & $f_{1}$ & $f_{2}$ & $f_{3}$ & $f_{4}$ & $f_{5}$ & $f_{8}$ & $f_{7}$ & $f_{8}$ & $f_{9}$ & $f_{10}$ \\
\hline$u_{1}$ & I & 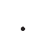 & . & . & . & . & $-I$ & $-\frac{1}{2}$ & . & . \\
\hline$u_{2}$ & . & I & . & . & . & $\cdot$ & . & . & . &. \\
\hline$u_{3}$ & . & 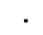 & I & . & . & . & 2 & I & . & . \\
\hline$u_{4}$ & . & . & $\cdot$ & I & $\dot{ }$ & · & $\cdot$ & . & . & . \\
\hline$u_{s}$ & . & . & - & - & I & i & $-i$ & - & - & $\cdot$ \\
\hline$u_{s}$ & : & - & . & • & : & 1 & -1 & $\cdot$ & $i$ & · \\
\hline$u_{8}$ & . & . & . & . & . & . & 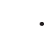 & $\frac{1}{2}$ & . & I \\
\hline
\end{tabular}

TABLE 20

Disomic gametic matrix associated with the $U_{1 \times 9}$ variables for the genotype $\left(\mathrm{a}_{1} \mathrm{~b}_{1}\right)_{2}\left(\mathrm{a}_{2} \mathrm{~b}_{2}\right)$

\begin{tabular}{|c|c|c|c|c|c|c|c|c|c|c|}
\hline & \multicolumn{10}{|c|}{ Gametes } \\
\hline & $\frac{a_{1} b_{1}}{a_{1} b_{1}}$ & $\frac{a_{2} b_{1}}{a_{2} b_{1}}$ & $\frac{a_{2} b_{2}}{a_{8} b_{8}}$ & $\frac{a_{1} b_{2}}{a_{1} b_{2}}$ & $\frac{a_{1} b_{1}}{a_{1} b_{2}}$ & $\frac{a_{2} b_{1}}{a_{1} b_{1}}$ & $\frac{a_{2} b_{2}}{a_{2} b_{1}}$ & $\frac{a_{1} b_{2}}{a_{2} b_{2}}$ & $\frac{a_{1} b_{1}}{a_{2} b_{2}}$ & $\frac{a_{1} b_{2}}{a_{2} b_{1}}$ \\
\hline$u_{1}$ & $\frac{1}{3}$ & $\cdot$ & & . & • & . & . & . & $\frac{2}{3}$ & $\cdot$ \\
\hline$u_{2}$ & $\frac{2}{3}$ & . & $\frac{1}{3}$ & . & & & $\cdot$ & . & & . \\
\hline$u_{3}$ & & - & & $\cdot$ & 青 & $\frac{1}{3}$ & & . & $\frac{1}{3}$ & . \\
\hline$u_{4}$ & $\frac{1}{3}$ & . & . & . & $\frac{1}{3}$ & & $\frac{1}{3}$ & & 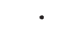 & . \\
\hline$u_{5}$ & $\frac{1}{3}$ & . & 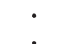 & 1 & 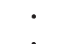 & $\frac{1}{3}$ & 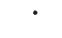 & $\frac{1}{3}$ & - & - \\
\hline $\begin{array}{l}u_{6} \\
u_{7}\end{array}$ & $\frac{1}{3}$ & $\frac{1}{3}$ & . & $\begin{array}{l}\frac{2}{3} \\
\frac{1}{3}\end{array}$ & : & $\frac{2}{3}$ & $\dot{v}$ & $\dot{ }$ & : & - \\
\hline$u_{8}$ & $\frac{1}{3}$ & 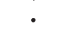 & . & 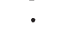 & . & . & . & . & . & $\frac{2}{3}$ \\
\hline
\end{tabular}


given in table 21. The variables $\mathrm{U}_{1 \times 8}$ as functions of $F_{1 \times 10}$ are given in table 22 , and the gametic matrix, $\mathrm{G}^{*}{ }_{\mathbf{8} \times \mathbf{1 0}}$ associated with $\mathrm{U}_{\mathbf{1 \times 8}}$ is given in table 23 .

TABLE $2 \mathrm{I}$

Disomic gametic matrix for the genotype $\left(\mathrm{a}_{1} \mathrm{~b}_{1}\right)\left(\mathrm{a}_{1} \mathrm{~b}_{2}\right)\left(\mathrm{a}_{2} \mathrm{~b}_{1}\right)$

\begin{tabular}{|c|c|c|c|c|c|c|c|c|c|c|}
\hline \multirow[b]{2}{*}{ Mode } & \multicolumn{10}{|c|}{ Gametes } \\
\hline & $\frac{a_{1} b_{1}}{a_{1} b_{1}}$ & $\frac{a_{2} b_{1}}{a_{2} b_{1}}$ & $\frac{a_{2} b_{2}}{a_{2} b_{2}}$ & $\frac{a_{1} b_{2}}{a_{1} b_{2}}$ & $\frac{a_{1} b_{1}}{a_{1} b_{2}}$ & $\frac{a_{2} b_{1}}{a_{1} b_{1}}$ & $\frac{a_{2} b_{2}}{a_{2} b_{1}}$ & $\frac{a_{1} b_{2}}{a_{2} b_{2}}$ & $\frac{a_{1} b_{1}}{a_{2} b_{2}}$ & $\frac{a_{1} b_{2}}{a_{2} b_{1}}$ \\
\hline $\begin{array}{r}\mathrm{I} \\
2 \\
3 \\
4 \\
5 \\
6 \\
7 \\
8 \\
9 \\
\mathrm{IO}\end{array}$ & $\begin{array}{l}\frac{1}{3} \\
\frac{1}{6} \\
\frac{1}{8} \\
\frac{1}{6} \\
\frac{3}{3} \\
\frac{3}{1} \\
\frac{1}{2} \\
\frac{1}{2}\end{array}$ & $\begin{array}{l}\frac{1}{3} \\
\dot{j} \\
. \\
.\end{array}$ & $\begin{array}{l}. \\
. \\
.\end{array}$ & $\begin{array}{l}\frac{1}{3} \\
. \\
\frac{1}{6} \\
. \\
. \\
\frac{1}{6}\end{array}$ & $\begin{array}{l}\frac{1}{3} \\
\frac{1}{6} \\
\frac{1}{2} \\
. \\
\dot{i} \\
\frac{1}{3} \\
\frac{1}{6} \\
\frac{1}{3}\end{array}$ & $\begin{array}{l}\frac{1}{3} \\
\frac{i}{6} \\
\frac{i}{2} \\
\frac{1}{3} \\
\frac{i}{6} \\
\frac{i}{3}\end{array}$ & 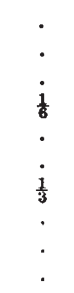 & $\begin{array}{l}\dot{5} \\
\dot{5} \\
\frac{1}{6} \\
\frac{1}{3} \\
\dot{5} \\
\dot{5} \\
.\end{array}$ & $\begin{array}{l}\dot{j} \\
\frac{i}{6} \\
\dot{b} \\
\dot{b} \\
\dot{i} \\
\frac{i}{3}\end{array}$ & $\begin{array}{l}\frac{1}{3} \\
\frac{\dot{1}}{3} \\
. \\
. \\
\dot{1} \\
\dot{\frac{1}{6}} \\
. \\
\end{array}$ \\
\hline & $\mathrm{D} \equiv$ & $\begin{array}{l}-2 \\
-1\end{array}$ & $\begin{array}{r}-I \\
.\end{array}$ & $\begin{array}{l}2 \\
.\end{array}$ & $-I$ & & & $\begin{array}{r}-I \\
I\end{array}$ & & \\
\hline
\end{tabular}

TABLE 22

$A$ set of estimable variables, $U_{1 \times 8}$ as functions of gametic mode frequencies, $F_{1 \times 10}$, for the genotype $\left(\mathrm{a}_{1} \mathrm{~b}_{1}\right)\left(\mathrm{a}_{1} \mathrm{~b}_{2}\right)\left(\mathrm{a}_{2} \mathrm{~b}_{1}\right)$

\begin{tabular}{|c|c|c|c|c|c|c|c|c|c|c|}
\hline & $f_{1}$ & $f_{2}$ & $f_{3}$ & $f_{4}$ & $f_{5}$ & $f_{6}$ & $f$ & $f_{8}$ & $f_{\theta}$ & $f_{10}$ \\
\hline$u_{1}$ & I & . & . & . & I & $-I$ & & . & . & I \\
\hline$u_{2}$ & . & I & & r. & . & . & $-I$ & . & $\cdot$ & $\cdot$ \\
\hline$u_{3}$ & . & . & I & 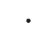 & . & . & 2 & I & . & . \\
\hline$u_{4}$ & . & . & 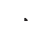 & I & -1 & 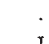 & 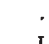 & • & . & . \\
\hline$u_{5}$ & : & . & . & . & I & $\begin{array}{l}\text { I } \\
\text { I }\end{array}$ & $\begin{array}{r}1 \\
-2\end{array}$ & 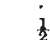 & : & i \\
\hline$u_{7}$ & . & . & . & . & . & & I & $-\frac{1}{2}$ & . & $-I$ \\
\hline$u_{8}$ & . & . & . & • & . & . & . & & I & \\
\hline
\end{tabular}

TABLE 23

Disomic gametic matrix associated with the $U_{1 \times 8}$ variables for the genotype $\left(\mathrm{a}_{1} \mathrm{~b}_{1}\right)\left(\mathrm{a}_{1} \mathrm{~b}_{2}\right)\left(\mathrm{a}_{2} \mathrm{~b}_{1}\right)$

\begin{tabular}{|c|c|c|c|c|c|c|c|c|c|c|}
\hline & \multicolumn{10}{|c|}{ Gametes } \\
\hline & $\frac{a_{1} b_{1}}{a_{1} b_{1}}$ & $\frac{a_{2} b_{1}}{a_{2} b_{1}}$ & $\frac{a_{2} b_{2}}{a_{2} b_{2}}$ & $\frac{a_{1} b_{2}}{a_{1} l_{2}}$ & $\frac{a_{1} b_{1}}{a_{1} b_{2}}$ & $\frac{a_{2} b_{1}}{a_{1} b_{1}}$ & $\frac{a_{2} b_{2}}{a_{2} b_{1}}$ & $\frac{a_{1} b_{2}}{a_{2} b_{2}}$ & $\frac{a_{1} b_{1}}{a_{2} b_{2}}$ & $\frac{a_{1} b_{2}}{a_{2} b_{1}}$ \\
\hline $\begin{array}{l}u_{1} \\
u_{2} \\
u_{3} \\
u_{4} \\
u_{5} \\
u_{6} \\
u_{7} \\
u_{8}\end{array}$ & $\begin{array}{l}\frac{3}{3} \\
\frac{1}{6} \\
\frac{1}{6} \\
1 \\
\frac{1}{3} \\
. \\
. \\
\frac{1}{2}\end{array}$ & $\begin{array}{r}\frac{1}{3} \\
1 \\
1 \\
6 \\
1 \\
-1 \\
-1 \\
-1 \\
-1 \\
-1 \\
1 \\
6\end{array}$ & $\begin{array}{l}\cdot \\
\dot{0} \\
i \\
i \\
i \\
i\end{array}$ & $\begin{array}{r}1 \\
-1 \\
-6 \\
-6 \\
-6 \\
6\end{array}$ & $\begin{array}{l}\frac{1}{3} \\
1 \\
1 \\
\frac{1}{1} \\
1 \\
6 \\
1 \\
6 \\
1 \\
6\end{array}$ & $\begin{array}{l}\frac{1}{3} \\
\frac{1}{6} \\
\frac{1}{6} \\
\frac{1}{6} \\
\frac{1}{1} \\
\frac{1}{2}\end{array}$ & $\begin{array}{r}1 \\
6 \\
-6 \\
-\frac{1}{6} \\
-\frac{1}{8}\end{array}$ & $\begin{array}{l}. \\
\dot{5} \\
\dot{5} \\
\frac{i}{6} \\
\frac{6}{6} \\
\frac{1}{6}\end{array}$ & $\begin{array}{r}i \\
\frac{1}{6} \\
\vdots \\
-j\end{array}$ & $\begin{array}{r}\frac{1}{3} \\
\frac{1}{3} \\
-\frac{1}{3} \\
\frac{2}{3} \\
1\end{array}$ \\
\hline
\end{tabular}


Double reduction and recombination frequencies are obtained from $\widehat{U}$ as follows :

$$
\begin{aligned}
\hat{a}_{a} & =\hat{u}_{2}+\hat{u}_{4}+\hat{u}_{5}-\hat{u}_{6}-\hat{u}_{7}+\hat{u}_{8} \\
\hat{a}_{b} & =\hat{u}_{2}+\hat{u}_{5}+\hat{u}_{8} \\
\hat{y}_{a b} & =\frac{1}{2}\left(\hat{u}_{3}+\hat{u}_{4}\right)+\hat{u}_{5}-\hat{u}_{7}+\hat{u}_{8}
\end{aligned}
$$

By combining disomic gametic matrices for genotypes from both isomorphic sets, the deficiency matrix can be reduced to a row vector of rank one. This deficiency row vector is the same as that found for disomic gametic matrices for genotypes digenic at one locus and trigenic at the other.

\section{NUMERICAL EXAMPLE}

For the numerical example we shall consider tomato trisomic data presented by Lesley (1937). The data represent a portion of the disomic progeny from the cross $(d \mathrm{PS})(\mathrm{D} p \mathrm{~S})(\mathrm{DP} s) \times(d p s)_{2}$, where $d=\mathrm{dwarf}, p=$ peach, and $s=$ compound inflorescence. These three loci have the order $d$-p-s in chromosome 2 of the tomato. We shall designate the chromosomal segments between loci " $d$ " and " $p$ " and between " $p$ " and " $s$ " as regions $I$ and 2 , respectively.

Two out of the five cultures exhibited poor germination and these yielded highly significant deviations from the expected $2: 1$ ratios for the genes $\mathrm{P}, p$ and $\mathrm{S}, s$. Therefore, the present analysis is based on the three remaining cultures, which yield the following data :

$$
\begin{array}{llll}
D P S=26 & D p s=12 & D P S=37 & D p S=70 \\
d p s=0 & d P S=57 & d p S=3 & d P s=9
\end{array}
$$

These data, although more satisfactory, are not wholly free from viability disturbances. The observed ratios are $D: d=145: 69$, $s: s=15^{6}: 5^{8}$, and $P: p=129: 85$. The corresponding $\chi^{2}$ s computed on a $2: 1$ theoretical ratio are ${ }_{\mathrm{D}} \chi^{2}{ }_{1}=0 \cdot 1 \mathrm{I}, \mathrm{s}_{\mathrm{s}} \chi^{2}{ }_{1}=3 \cdot 72$, and ${ }_{\mathrm{P}} \chi^{2}{ }_{1}=3 \cdot 95$. The deficiency of non-peach $(P)$ is the most surprising disturbance of the data.

Lesley (1937) gave the correct gametic matrix which in this paper is presented in table $\mathrm{Ir}$. By ignoring double crossing over and using various fractions of the total data (all five cultures) he estimated the recombination percentages to be 5.9 for region $1,26 \cdot 0$ for region 2 and $30 \cdot 0$ for the region from " $d$ " to " $s$ " ignoring " $p$ ".

In the present analysis the estimation procedure outlined by Fisher (1947) is used to obtain maximum likelihood estimates of the five different modes of gamete formation and subsequently estimates of the various recombination values.

Fairly accurate initial trial values for mode frequencies are obtained by calculating the recombination value for each region separately. Thus, the recombination values $0 \cdot 064,44^{2}$ and $0 \cdot 334,367$ are computed for regions $\mathrm{I}$ and 2, respectively. The trial values for frequencies of modes 4 and 5 are obtained by halving the expected double crossover frequency, $0.021,547$. Hence, the initial trial frequencies are $f_{1}=$ $0.622,737, f_{2}=0.042,895, f_{3}=0.312,820$ and $f_{4}=f_{5}=0.010,774$. 


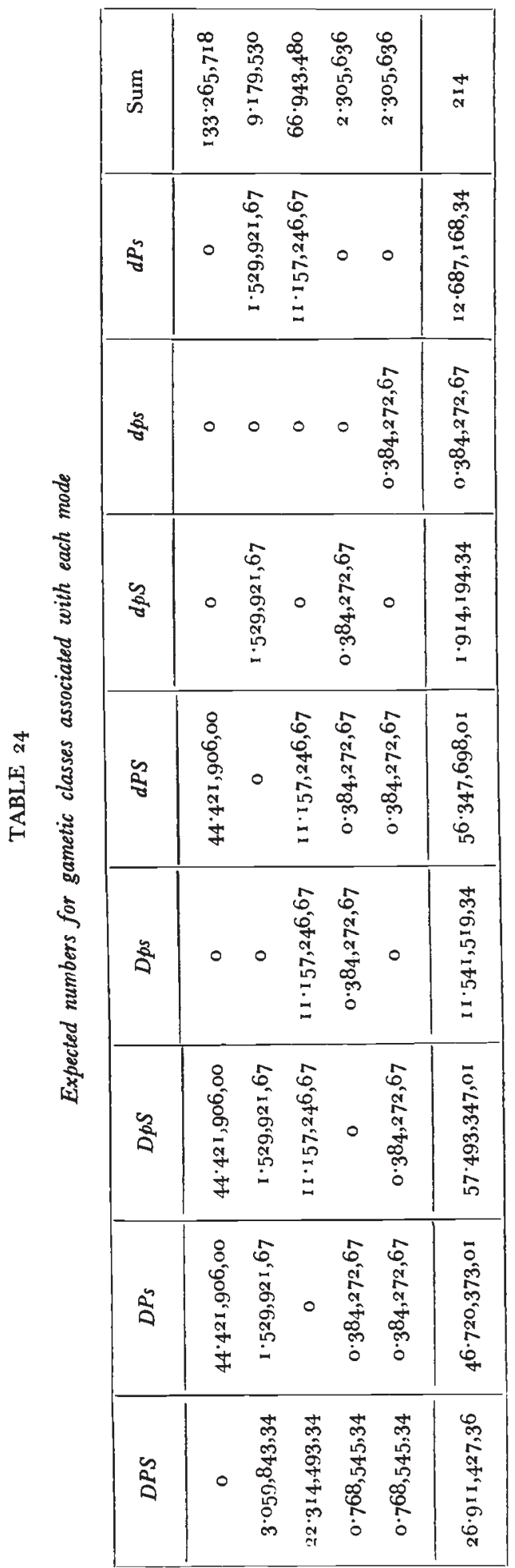


These frequencies (see table 24) are used to obtain the expected numbers for the gametic classes associated with each mode.

The information matrix of $\theta_{i}$ is given in table 25, where $\theta_{i}$ are the introduced symmetrical variables defined by the relations

(see Fisher, 1947).

$$
\frac{\partial m_{k}}{\partial \theta_{i}}=f_{i}\left(\frac{\partial m_{k}}{\partial f_{i}}-\sum f_{i} \frac{\partial m_{k}}{\partial f_{i}}\right)
$$

\begin{tabular}{crrrr}
\multicolumn{5}{c}{ TABLE 25} \\
& Information matrix & \\
$28 \cdot 589,519,20$ & $-3 \cdot 079,692,46$ & $-24 \cdot 271,744,36$ & $-0 \cdot 767,494,23$ & $-0 \cdot 470,588,15$ \\
& $1 \cdot 45^{2}, 242,78$ & $1 \cdot 307,959,21$ & $0 \cdot 308,197,59$ & $0.011,292,94$ \\
& & $22 \cdot 533,525,67$ & $0 \cdot 363,58,66$ & $0 \cdot 066,676,81$ \\
& & & $0 \cdot 092,825,32$ & $0.002,888,67$ \\
& & $0 \cdot 389,729,73$
\end{tabular}

By omitting the fifth row and column the reduced matrix can be inverted to give the covariance matrix (table 26) for the remaining $\theta_{i}$.

TABLE 26

Covariance matrix of $\theta_{i}$

$\begin{array}{rrrr}2 \cdot 567,461,65 & 2 \cdot 576,075,9 \mathrm{I} & 2 \cdot 574, \mathrm{I} 54,05 & 2 \cdot 592,545, \mathrm{I} 6 \\ & 4 \cdot 9 \mathrm{r} 8,510,36 & 2 \cdot 57 \mathrm{I}, 647,06 & -5 \cdot 103,735,69 \\ & & 2 \cdot 628,289,30 & 2 \cdot 450,544,05 \\ & & & 39 \cdot 555,447,32\end{array}$

Finally the adjustments $\Delta f_{1}=0 \cdot 009,627, \quad \Delta f_{2}=-0 \cdot 008,798$, $\Delta f_{3}=-0.016,434, \quad \Delta f_{4}=0.026,559, \quad$ and $\Delta f_{5}=-0.010,954$ are obtained giving rise to new trial values $f_{1}=0.632,364, f_{2}=0.034,097$, $f_{3}=0 \cdot 296,386, f_{4}=0 \cdot 037,333, f_{5}=-0 \cdot 000$, I 80 .

TABLE 27

Covariance matrix for $\mathrm{f}_{i}$

$$
\begin{aligned}
& \text { o.00 , }, 893,5 \\
& \begin{array}{rrr}
-0 \cdot 000,2 \text { I } 5,7 & -0 \cdot 001,45 \mathrm{I}, 5 & -0 \cdot 000,228,5 \\
0 \cdot 004,305, \mathrm{I} & -0 \cdot 000,684,8 & -0 \cdot 003,404,9 \\
& 0 \cdot 002,802, \mathrm{I} & -0 \cdot 000,667,9 \\
& & 0 \cdot 004,301,0
\end{array} \\
& \begin{array}{r}
0 \cdot 000,002,3 \\
-0 \cdot 000,000,3 \\
0 \cdot 000,002,2 \\
0 \cdot 000,000,3 \\
-0 \cdot 000,005,1
\end{array}
\end{aligned}
$$

The process is repeated and another set of adjustments are obtained : $\Delta f_{1}=0.002,605, \quad \Delta f_{2}=-0.003,680, \quad \Delta f_{3}=0.000,705, \quad \Delta f_{4}=$ $0 \cdot 000,189$, and $\Delta f_{5}=0 \cdot 000,180$. These adjustments are regarded as sufficiently negligible. The final mode frequency estimates are then $\hat{f}_{1}=0.634,969, \hat{f}_{2}=0.030,4 \mathrm{I} 7, \hat{f}_{3}=0.297,09 \mathrm{I}, \hat{f}_{4}=0.037,523$, $f_{5}=0 \cdot 000,000$. The covariance matrix associated with these estimates is given in table 27 .

The recombination fraction for region $\mathrm{I}$ is estimated as $\hat{y}_{1}=$ $\hat{f}_{2}+\hat{f}_{4}+\hat{f}_{5}=0.067,940 \pm 0.042,323$ and for region $2, \hat{y}_{2}=\hat{f}_{3}+\hat{f}_{4}+\hat{f}_{5}=$ $0 \cdot 334,61_{4} \pm 0 \cdot 075,942$. The estimated recombination fraction between the " $d$ " and " $s$ " loci, ignoring the " $p$ " locus, is $\hat{y}_{\mathrm{ds}}=\hat{f}_{2}+\hat{f}_{3}+\hat{f}_{5}=$ $0 \cdot 327,508 \pm 0 \cdot 075,73^{8}$. The fact that this fraction is smaller than $\hat{y}_{2}$ 
is due to the exceptionally large fraction of "progressive" double crossovers, i.e. $\hat{f}_{4}=0 \cdot 037,5^{2} 3$. The total frequency of double crossing over, $\hat{y}_{12}=\hat{f}_{4}+\hat{f}_{5}=0.037,523 \pm 0.065,54^{8}$, is considerably larger than the expected frequency of double crossing over on the basis of no interference, i.e. $\hat{y}_{1} \cdot \hat{y}_{2}=0 \cdot 022,734$. Apparently, all of the double crossovers involve only two chromosomes.

These data have been analysed merely to present a numerical example. Too much confidence should not be placed in these estimates because of viability disturbances and the large standard errors associated with the estimates.

\section{DISCUSSION}

The most extensive experimental studies involving linkage in trisomic inheritance are those of Bridges and Anderson (1925) and Redfield (I930 and I932). The primary purpose of these studies was to compare recombination values for the same chromosomal region in diploid and triploid Drosophila melanogaster. By making such a comparison it was hoped to evaluate the possibility of sister-strand crossing over. Taken together, these experiments involved essentially the entire length of each of the three major chromosomes.

The experimental procedure consisted of crossing triploid females, which contained the appropriate mutants, with completely recessive diploid males. At the same time control matings between heterozygous diploid females and completely recessive males were made, and from these matings disomic linkage data involving the same loci were obtained.

Bridges and Anderson (I 925) concentrated on the X-chromosome and identified 182 exceptional diploid female progeny. Thus, they evaluated disomic gametes from the triploid female parent and compared linkage data from these disomic gametes with the corresponding linkage data from the diploid control crosses. Redfield, on the other hand, concentrating on the second and third chromosomes, used monosomic gametes, from which recombination values were computed and compared with the corresponding estimates obtained from the diploid crosses.

It was generally found that recombination values estimated from diploid and triploid crosses were different for a given chromosomal region. However, these differences were quite variable and it was, therefore, impossible to make inferences regarding the phenomenon of sister-strand crossing over. Nevertheless, these studies have led to further investigations of factors influencing recombination frequencies (Schultz and Redfield, I95 I).

What are the ideal conditions under which a comparison of crossing over in a trisome with that in a disome can be accurately made? Let us first consider the use of trisomics and then, briefly discuss the Drosophila triploid case. The problem common to both situations is to obtain unbiased recombination estimates. 
With trisomics there are at least two possible sources of disturbance which need to be examined. These are (i) viability of mutants, and (ii) non-random disjunction of homologous chromosomes in the trisomic organism (see Rhoades, 1933, and Mather, I933).

In order to detect and to some extent cope with these disturbance factors, it is necessary to obtain data from each of the three following sources :

(i) "balanced" disomic $\times$ disomic control crosses,

(ii) disomic progeny from trisomic $\times$ disomic crosses,

and (iii) trisomic progeny from trisomic $\times$ disomic crosses.

The experiments yielding such data should involve the same chromosomal segments, have, as nearly as possible, the same genetic background, and be conducted under identical conditions.

For the disomic $\times$ disomic control crosses, the use of "balanced" experiments allows an estimation of recombination values free from viability effects.

If the viability effects cause significant disturbances among either or both classes of progeny from the trisomic $\times$ disomic cross, the problem is difficult and it is not clear how unbiased recombination estimates can be obtained.

If the viability effects are negligible, then the comparison of recombination values computed from monosomic and disomic gametes permits an examination of the assumption of random disjunction of homologous chromosomes in the trisomic parent. Only if the two classes of gametes yield similar recombination values, but values which are significantly different from those derived from the control crosses, can it be concluded that there are factors other than those listed above operating to cause different recombination values at the disomic and trisomic levels.

When Drosophila triploids are used, the problem of ensuring unbiased recombination estimates is much more difficult, even if it can be assumed that viability effects are negligible. There are eight different chromosomal types of progeny resulting from the cross 우 triploid $\times \sigma$ diploid. These are the result of the combination (distinctly non-random) of four egg types IX+IA, IX+2A, $2 \mathrm{X}+\mathrm{IA}$, and $2 \mathrm{X}+2 \mathrm{~A}$ with the two types of sperms $\mathrm{IX}+\mathrm{IA}$ and $\mathrm{I} \mathrm{Y}+\mathrm{IA}$ (where $\mathrm{X}$ and $\mathrm{Y}$ are the sex chromosomes and $\mathrm{A}$ represents a haploid set of autosomes). Absence of bias is ensured only when recombination values for a given region are similar for the eight different classes of progeny. However, it is impossible to examine this condition since certain types cannot be tested.

Thus, it would appear that if an accurate comparison of crossing over in a trisome with crossing over in a corresponding disome is to be made, it would be best to use trisomics in which random disjunction of homologous chromosomes occurs and to use mutants which have unimpaired viability. 
A second problem pertains to the kind of trisomic genotype which is used for a study of linkage. The ideal is one which is trigenic at each locus. However, this genotype can seldom be obtained. Bridges and Anderson (1925) obtained an essentially equivalent genotype using only two alleles per locus. This was accomplished by marking the ends of the chromosomal regions by two very closely linked loci. In this way they were able to include four contiguous regions in the $\mathrm{X}$-chromosome of Drosophila melanogaster from $y=$ yellow $(0 \cdot 0)$ to $B=\operatorname{bar}\left(57^{\circ}\right)$. Using the same technique in one experiment, Redfield (I930) included five contiguous regions on the third chromosome of Drosophila melanogaster from se $=$ sepia $(26 \cdot 0)$ to $M=$ minute (IOI). In these cases the estimation procedure is simple and efficient in the sense that all data are utilised.

More often the experimenter will necessarily use trisomic genotypes which are digenic at all loci and in which the above procedure cannot be utilised. Such was the case in certain of Redfield's studies of the third chromosome and in her studies of the second chromosome. Digenic genotypes were also used in maize experiments (Rhoades, 1933) and in tomato experiments (Lesley, 1937). In all of these studies approximate estimation procedures were applied to data resulting from the monosomic gametes of the trisomic organism. Redfield computed recombination values for each region separately by multiplying the apparent recombination frequency by $\frac{3}{2}$. No attempt was made to estimate multiple crossover frequencies. The constant $\frac{3}{2}$. is the appropriate constant to use for this approximation, but the estimating procedure does not utilise all of the available information and is not the maximum likelihood estimate.

To consider the appropriate estimation procedure for obtaining the maximum amount of information from crosses involving trisomic genotypes which are digenic at all loci let us assume: (i) there are $l$ loci involved, $l>2$, (ii) the cross trisomic $\times$ disomic (completely recessive) is made, and (iii) linkage data fror both $\mathrm{disomic}_{\text {ind }}$ trisomic progeny are obtained. Maximum likeli.. . s esisinates can be computed by a procedure outlined by Fisher (1937). However, as pointed out earlier, computational limits are imposed by the dimensions of the information matrix. Hence analyses must be made on genotypes involving groups of genes in which the size of the group depends to some extent on the type of progeny. Thus, for disomic progeny, data can be analysed for genotypes involving up to four loci. Such analyses allow an examination of frequencies of various classes of multiple crossovers, and in addition, allow estimation of recombination values for any given pair of loci. For trisomic progeny, data can be analysed for genotypes involving two loci. Such analyses permit double reduction frequencies to be estimated for each locus, and permit estimation of recombination values for appropriate pairs of loci.

Thus, by utilising information obtained from both types of progeny 
it may be possible to locate the relative position of the centromere with respect to the loci, to compare recombination estimates for any given pair of loci for both classes of progeny, and to estimate the frequencies of various kinds of multiple crossovers.

\section{REFERENCES}

BRIDGes, C. B., AND ANDERSON, E. G. 1925. Crossing over in the X-chromosomes of triploid females of Drosophila melanogaster. Genetics, $10,4^{1}$ 8-441.

DE Winton, D., AND haldane, J. B. S. I931. Linkage in the tetraploid Primula sinensis. 7. Genet., 24, I 2 I-144.

FISHER, R. A. I947. The theory of linkage in polysomic inheritance. Phil. Trans. Roy. Soc., B, 233, 55-87.

FISHER, R. A. 1949. The linkage problem in a tetrasomic wild plant, Lythrum salicaria. Proc. 8th int. Congr. Gen., Hereditas suppl., pp. 225-233.

FISHER, R. A. 1950. A class of enumerations of importance in genetics. Proc. Roy. Soc., B., 136, 509-520.

LESLEY, J. W. I937. Crossing over in tomatoes trisomic for the "A " or first chromosome. Genetics, 22, 297-306.

MATHER, K. I933. The relation between chiasmata and crossing over in diploid and triploid Drosophila melanogaster. 7. Genet., 27, 243-26o.

REDFIELD, H. I930. Crossing over in the third chromosomes of triploids of Drosophila melanogaster. Genetics, 15, 205-252.

REDFIELD, H. I932. A comparison of triploid and diploid crossing over for chromosome II of Drosophila melanogaster. Genetics, I7, I37-152.

RHOADES, M. M. 1933. An experimental and theoretical study of chromatid crossing over. Genetics, I8, 535-555.

sansome, F. W. 1933. Chromatid segregation in Solanum lycopersicon. 7. Genet., 27, $105-133$.

SCHULTZ, J., AND REDFIELD, H. 195r. Interchromosomal effect on crossing over in Drosophila. Cold Spring Harbor Symp. Quant. Biol., 15, 1 75-197.

sömmE, A. s. I930. Genetics and cytology of the tetraploid form of Primula sinensis. 7. Genet., 23, 447-509. 